\title{
Stage II Bladder Squamous Cell Carcinoma AJCC v6 and v7
}

National Cancer Institute

\section{Source}

National Cancer Institute. Stage II Bladder Squamous Cell Carcinoma A/CC v6 and v7. NCI Thesaurus. Code C4994.

Stage II includes: (T2a, N0, M0); (T2b, N0, M0). T2a: Tumor invades superficial muscle (inner half). T2b: T umor invades deep muscle (outer half). N0: No regional lymph node metastasis. M0: No distant metastasis. (AJCC 6th and 7th eds.) 